\title{
Citología Endometrial en la Gata (Felis catus) Durante el Diestro
}

\author{
Endometrial Cytology in the Female Cat (Felis catus) During Diestrus
}

\author{
Alfonso Sánchez R. ${ }^{1,2,3}$, Loreto Stamatiu S. ${ }^{1}$
}

\section{Resumen}

El propósito del estudio fue describir y cuantificar los hallazgos citológicos en el endometrio de la gata (Felis catus). Se obtuvieron 20 tractos genitales mediante ovariohisterectomía. Para establecer el estado del ciclo estral se evaluó la citología vaginal y se registraron las estructuras ováricas. Se determinó que todas las hembras estaban en fase luteal. De acuerdo con la presencia de cuerpos lúteos y folículos, se propuso una clasificación de la fase luteal en diestro temprano: cuerpos lúteos y folículos de $2 \mathrm{~mm}$ $(n=3)$, diestro medio: cuerpos lúteos sin folículos $(n=4)$, y diestro tardío: cuerpos lúteos y folículos de $0.5-1 \mathrm{~mm}(\mathrm{n}=13)$. En los frotis de mucosa uterina se presentaron patrones morfológicos homologables a los descritos en la especie canina, destacando que es posible verificar una disminución de la proporción de células epiteliales endometriales normales y un incremento en la degeneración celular hacia la etapa final de la fase luteal $(\mathrm{p}<0.05)$.

Palabras clave: citología endometrial; endometrio; gata; cuerpo lúteo

\section{AbSTRaCT}

The purpose of the study was to describe and quantify cytological findings in the cat's endometrium (Felis catus). Twenty genital tracts were obtained by ovariohysterectomy. To establish the status of the estrous cycle, vaginal cytology was evaluated and ovarian structures were recorded, resulting that all females were in the

${ }^{1}$ Facultad de Recursos Naturales y Medicina Veterinaria, Escuela de Medicina Veterinaria, Universidad Santo Tomás, Viña del Mar, Chile

${ }^{2}$ Facultad de Medicina Veterinaria y Agronomía, Escuela de Medicina Veterinaria, Universidad de Las Américas, Viña del Mar, Chile

${ }^{3}$ E-mail: profesanchez@gmail.com

Recibido: 8 de marzo de 2017

Aceptado para publicación: 7 de julio de 2017 
luteal phase. According to the presence of corpora lutea and follicles, a classification of the luteal phase was proposed: early diestrus: corpora lutea and follicles of $2 \mathrm{~mm}(\mathrm{n}=3)$, mid-diestrus: corpora lutea without follicles $(\mathrm{n}=4)$, and late diestrus: corpora lutea and follicles $0.5-1 \mathrm{~mm}(\mathrm{n}=13)$. In the smears of the uterine mucosa, morphological patterns comparable to those described in the canine species were observed, emphasizing that it is possible to verify a decrease in the proportion of normal endometrial epithelial cells and an increase in cellular degeneration towards the final stage of the luteal phase $(\mathrm{p}<0.05)$.

Key words: endometrial cytology; endometrium; queen; corpus luteum

\section{INTRODUCCIÓN}

La gata (Felis catus) es una hembra poliéstrica estacional que cicla continuamente cada 4 a 30 días si es expuesta a un periodo constante de 14 horas de luz por día (Verstegen, 1998). Si bien se ha demostrado que la ovulación es inducida por la cópula (Tsutsui et al., 2009), también se ha descrito la ocurrencia de ovulación en gatas sin estimulación vaginal (Gudermuth et al., 1997). Posterior a la ovulación ocurre la formación de los cuerpos lúteos, estructuras responsables de la secreción de progesterona, hormona que durante el diestro se encuentra en niveles plasmáticos superiores a $1.5 \mathrm{ng} / \mathrm{ml}$. La fase lútea felina presenta dos alternativas fisiológicas: en ausencia de gestación se habla de pseudopreñez, la cual raramente arroja signología clínica y dura en promedio 45 días (Tsutsui y Stabenfeldt, 1993). La otra alternativa es la gestación y tiene una duración promedio de 66 días (Sánchez y Silva, 2002).

La evaluación clínica del aparato reproductor de la gata se realiza como procedimiento rutinario para estimar la capacidad reproductiva y para detectar patologías que puedan afectan la fertilidad. Este procedimiento viene adquiriendo particular relevancia debido a la creciente crianza de gatos de raza (Romagnoli, 2006).

Una herramienta diagnóstica importante en teriogenología es la citología endometrial, la cual tiene amplia aplicación en diversas especies, especialmente para la identificación de endometritis clínica y subclínica (Walter et al., 2012; Gilbert y Santos, 2016). En la especie canina se ha reportado su utilización para el diagnóstico de hiperplasia endometrial quística, endometritis y neoplasias (Root Kustritz et al., 2006; Fontaine et al., 2009); sin embargo, la descripción citológica endometrial en la especie felina es escasa.

El propósito de este estudio fue describir y cuantificar los hallazgos citológicos en el endometrio de gatas, relacionándolos con la etapa del ciclo estral, establecida por citología vaginal y presencia de estructuras ováricas.

\section{Materiales y Métodos}

Durante la estación estival del hemisferio sur, se colectaron los tractos reproductivos de 20 gatas domésticas, clínicamente sanas, de entre 1 y 6 años, con un peso promedio de $2.89 \pm 0.71 \mathrm{~kg}$. Las hembras fueron sometidas a ovariohisterectomía en un plan de esterilización voluntaria en en el Hospital Clínico Veterinario de la Universidad Santo Tomás de Viña del Mar, Chile. Previo a la cirugía, se les practicó una ecografía abdominal para descartar gestación según Zambelli y Prati (2006), y citología vaginal para estimar el estado del ciclo estral, según Mills et al. (1979).

Los órganos reproductivos recuperados fueron lavados con suero fisiológico. Las muestras para citología endometrial se obtu- 


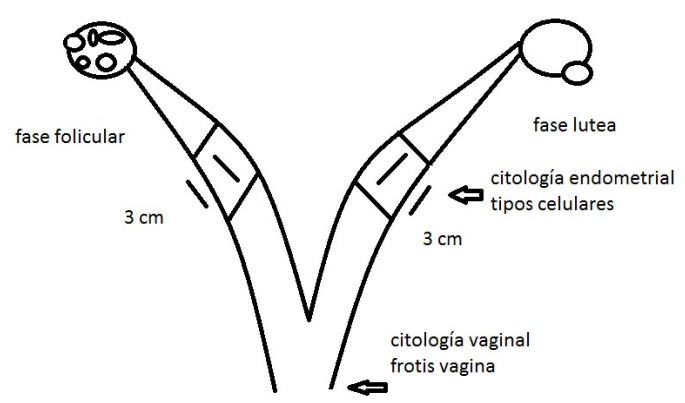

Figura 1. Esquema de la toma de muestras para la citología endometrial

vieron directamente de la mucosa uterina, mediante una incisión de aproximadamente $3 \mathrm{~cm}$ de largo en la zona media de cada cuerno uterino (Figura 1). La tórula estéril fue humedecida con suero fisiológico y se dirigió hacia anterior y posterior realizando una suave presión y rotación sobre el endometrio, para luego extender el material en un portaobjeto. Las muestras se tomaron en duplicado de ambos cuernos uterinos. Los frotis fueron fijados y teñidos con una tinción hematológica comercial (Diff Quick ${ }^{\circledR}$, Hartman Leddon).

La observación y cuantificación de los hallazgos morfológicos se efectuó con un microscopio óptico y con objetivos de 40 y 100X. En cada muestra se evaluaron seis campos microscópicos. Se tomó como referencia las descripciones de citología endometrial canina, donde las células epiteliales se clasificaron en células epiteliales endometriales normales (CEEN), células epiteliales endometriales degenerativas (CEED), agrupaciones celulares endometriales o grupos celulares normales (GCEN) cuando se visualizaban grupos conformados por más de 20 células, y grupos de células endometriales degenerativas (GCED), cuando además se visualizaban células en grupo sin estructura definida. Además, se registró la presencia de detritus celulares y de mucus.
En forma adicional, se registró la presencia de folículos y cuerpos lúteos en ambos ovarios, tomándose las medidas con un pie de rey. Los ovarios fueron fijados posteriormente en formalina y se hicieron cortes longitudinales para describir las estructuras presentes en la región interna de cada gónada.

Los recuentos de la citología endometrial para CEEN y CEED fueron expresados como porcentajes y para la presencia de GCE, GCED, detritus celulares y mucus se establecieron categorías cualitativas (ausencia, poca, moderada y abundante). Los datos de recuentos celulares se agruparon en diestro temprano, diestro medio y diestro tardío. Los datos porcentuales fueron transformados a valores angulares (ángulo $=$ arcoseno $\mathrm{x}$ ) para llevarlos a la distribución normal y realizar un análisis unilateral de la varianza (Zar, 1999). Las diferencias se estimaron mediante la prueba de hipótesis específica de Tukey. Los programas empleados fueron Prisma ${ }^{\circledR} 5.0$ y Excel ${ }^{\circledR}$.

\section{Resultados y Discusión}

La ecografía abdominal permitió constatar la ausencia de gestación en las 20 gatas del estudio. La citología vaginal arrojó un predominio de células parabasales $(35.5 \pm 21.8)$ e intermedias $(37.9 \pm 15.3)$, sobre las superficiales (26.6 \pm 16.4$)$, sugiriendo el estado de diestro en las hembras (Mills et al., 1979). Esto fue corroborado en la inspección de los ovarios, donde todas las hembras (20/20) presentaron cuerpos lúteos con diámetros que fluctuaron entre 2 y $3 \mathrm{~mm}$. El promedio de cuerpos lúteos por hembra fue de $6.4 \pm 3.9$, valores levemente superiores a los descrito por Tsutsui et al. (2009).

Se pudieron identificar folículos entre 0.5 y $2 \mathrm{~mm}$, los cuales fueron observados en el $80 \%$ de las hembras (16/20). En la gata se consideran folículos preovulatorios aquellos con diámetros sobre 2 mm (Sánchez y Silva, 
Cuadro 1. Recuentos de células endometriales normales (CEEN) y degenerativas (CEED), y presencia o ausencia de grupos de células endometriales normales (GCE) o degenerativas (GCED), detritus y mucus en gatas en distintas etapas de la fase luteal del ciclo de la gata doméstica

\begin{tabular}{lcccccc}
\hline $\begin{array}{l}\text { Etapa de } \\
\text { diestro }\end{array}$ & $\begin{array}{c}\text { CEEN } \\
(\%)\end{array}$ & $\begin{array}{c}\text { CEED } \\
(\%)\end{array}$ & GCE & GCED & Detritus & Mucus \\
\hline $\begin{array}{l}\text { Temprano } \\
(\mathrm{n}=3)\end{array}$ & $81.2 \pm 1.2^{\mathrm{a}}$ & $18.9 \pm 1.2^{\mathrm{a}}$ & + & + & + & ++ \\
$\begin{array}{l}\text { Medio } \\
(\mathrm{n}=4)\end{array}$ & $70.9 \pm 17.4^{\mathrm{a}}$ & $27.7 \pm 18.0^{\mathrm{a}}$ & ++ & + & + & + \\
$\begin{array}{l}\text { Tardío } \\
(\mathrm{n}=13)\end{array}$ & $64.6 \pm 17.1^{\mathrm{b}}$ & $35.4 \pm 17.0^{\mathrm{b}}$ & +++ & + & ++ & ++ \\
\hline
\end{tabular}

$a, b$ Superíndices diferentes dentro de columnas indican diferencia significativa $(p<0.05)$

+: Poca presencia; ++: Moderada presencia; +++: Abundante presencia

2003; Bristol-Gould y Woodruff, 2006). De este modo, según los hallazgos de presencia y tamaño de folículos en concomitancia con presencia de cuerpos lúteos, se propone la siguiente categorización de la fase luteal (diestro): Diestro temprano: cuerpos lúteos y folículos de $2 \mathrm{~mm}$; Diestro medio: cuerpos lúteos sin folículos; y Diestro tardio: cuerpos lúteos y folículos de 0.5-1 mm. De este modo, el 15\% (3/20) de las gatas evaluadas habrían estado en diestro temprano, 20\% $(4 / 20)$ en diestro medio y $65 \%$ (13/20) en diestro tardío.

Las CEEN no pudieron ser adecuadamente subdivididas en epitelio luminal y epitelio glandular, principalmente debido a las semejanzas morfológicas, concordante con lo señalado por Watts et al. (1998). Las CEEN se caracterizaron por presentar dos ejes, uno mayor y otro menor, observándose células ovaladas, con un núcleo central o hacia un polo de la célula, levemente ovalado o redondo. Además, fue frecuente observarlas en monocapas, agrupadas y con formas acinares. Las células aisladas se apreciaban con citoplasma, núcleo y nucléolo bien diferenciado, con una relación núcleo citoplasma similar y un patrón de cromatina levemente granular (Figura 2A).
Las CEED presentaban forma irregular, citoplasma con pequeñas vacuolas, con deformaciones y núcleos picnóticos, con pérdida de su forma o sin presencia de núcleo (Figura 2B). Cabe destacar la presencia de agrupaciones celulares normales (Figura 2C) y degenerativas (Figura 2D), las cuales estuvieron presentes durante toda la fase lútea, al igual que la presencia de detritus celulares y mucus.

Las observaciones registradas en el presente estudio coinciden con las características descritas para la citología endometrial canina por varios autores (Watts et al., 1998; Groppetti et al., 2010; Raskin y Meyer, 2010).

En el Cuadro 1 se presentan los recuentos porcentuales de CEEN y CEED, así como la presencia o ausencia de GCE, GCED, detritus y mucus obtenidos en las citologías endometriales en gatas a través de la fase luteal del ciclo estral. Destaca la mayor presencia de CEEN en el diestro temprano y medio, respecto del diestro tardío $(\mathrm{p}<0.05)$ y la mayor cantidad de CEED en el diestro tardío respecto del diestro medio y temprano $(\mathrm{p}<0.05)$. Watts et al. (1998) describen un incremento significativo de CEED durante el diestro respecto del estro en hembras cani- 

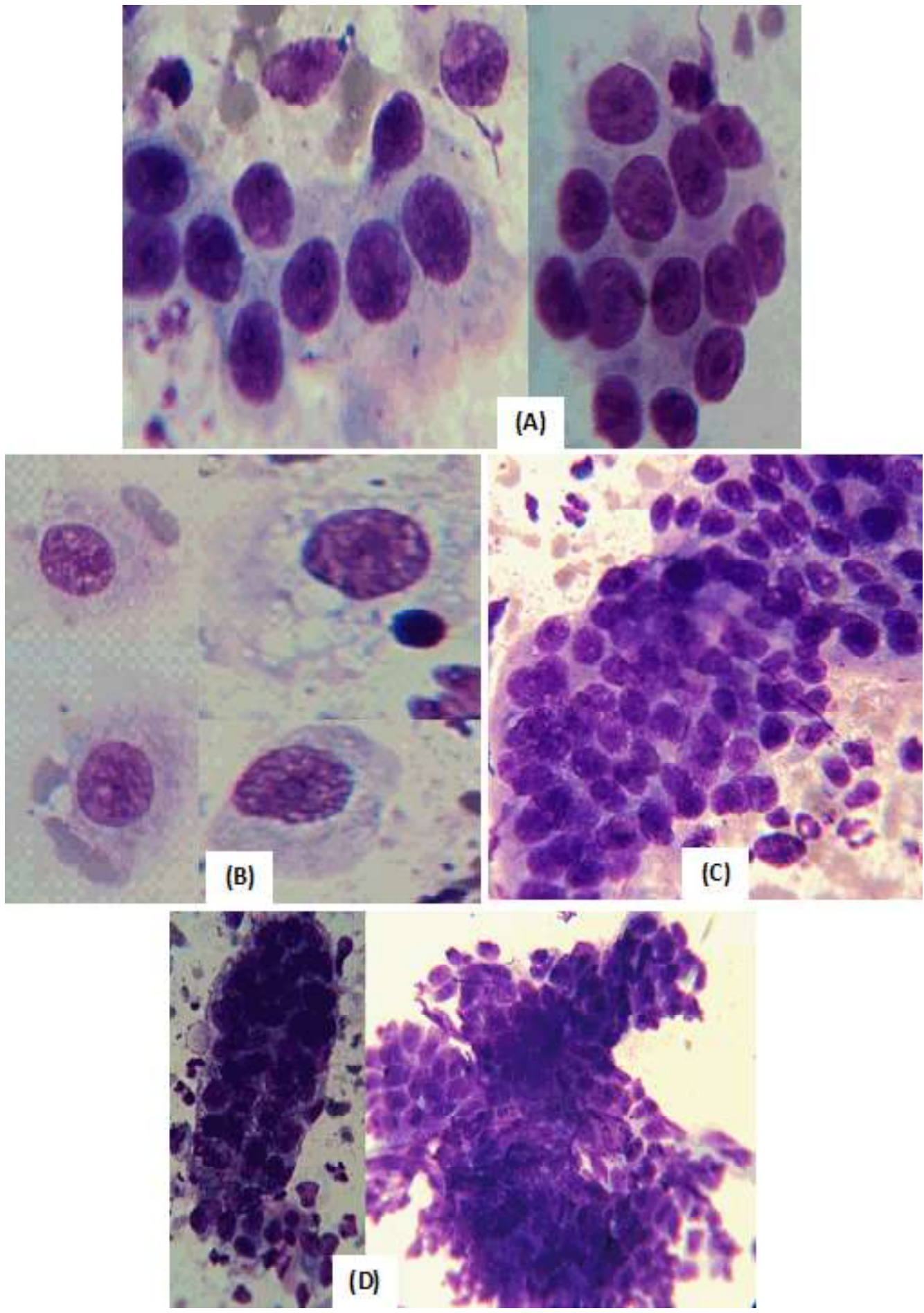

Figura 2. Células epiteliales endometriales de la gata durante la fase de diestro del ciclo estrual. Microscopio óptico 100X. (A). Células epiteliales endometriales normales con núcleo levemente ovalado y nucléolo redondo, la cromatina se observa levemente granular. (B). Células epiteliales endometriales degenerativas. Se observa núcleo y citoplasma con vacuolas, además de cambios en la estructura celular. (C). Agrupación de células epiteliales endometriales normales. Se observan núcleos redondos u ovalados con cromatina bien marcada. (D). Agrupación de células epiteliales endometriales degenerativas. Se observa pérdida de la relación núcleo-citoplasma 
nas. Así también, se destaca la presencia de GCE, GCDE, detritus celulares y mucus en todas las etapas de la fase luteal.

Estos eventos se podrían explicar tomando como referencia lo ocurrido en la perra; en la cual, a través del ciclo estral, el revestimiento uterino experimenta una serie de modificaciones macroscópicas, microscópicas y moleculares, cambios que se encuentran asociados principalmente a la influencia de estrógenos y progesterona (Fernandes et al., 1989; Schlafer, 2012). En la fase estrogénica ocurre proliferación celular e incremento de la vascularización, mientras que en la fase progestacional (diestro) el endometrio presenta dos etapas principales de crecimiento y otra de diferenciación (Barrau et al., 1975), en tanto que desde el diestro medio hasta el anestro temprano se caracteriza por la presencia de eventos degenerativos y regenerativos (Groppetti et al., 2010).

\section{Conclusiones}

Las células del epitelio endometrial de la gata presentan patrones morfológicos homologables a los descritos en la especie canina, destacando que es posible verificar un incremento en la degeneración celular hacia la etapa final de la fase luteal.

\section{Literatura Citada}

1. Barrau M, Abel J, Verhage H, Tietz W. 1975. Development of the endometrium during the estrous in the bitch. Am J Anat 142:47-65. doi: 10.1002/ aja.1001420105

2. Bristol-Gould S, Woodruff T. 2006. Folliculogenesis in the domestic cat (Felis catus). Theriogenology 66: 5-13. doi: 10.1016/j.theriogenology.2006.03.019

3. Fernandes $P$, Bowen $R$, Sawyer $H$, Nett T, Gorell T. 1989. Concentration of receptors for estradiol and progesterone in canine endometrium during estrus and diestrus. Am J Vet Res 50: 64-67.

4. Gilbert R, Santos N. 2016. Dynamics of postpartum endometrial cytology and bacteriology and their relationship to fertility in dairy cows. Theriogenology 85 : 1367-1374. doi: 10.1016/j.theriogenology.2015.10.045

5. Groppetti D, Pecile A, Arrighi, Di Giancamillo A, Cremonesi F. 2010. Endometrial cytology and computerized morphometric analysis of epihitelial nuclei: a usefull tool for reproductive diagnosis in the bitch. Theriogenology 73 : 927-941. doi: 10.1016/j.theriogenology.2009.11.019

6. Gudermuth D, Newton L, Daels P, Concannon P. 1997. Incidence of spontaneous ovulation in young, grouphoused cats based on serum and faecal concentrations of progesterone. J Reprod Fert Suppl 51: 177-184.

7. Mills J, Valli V, Lumsden J. 1979. Cyclical changes of vaginal cytology in the cat. Can Vet J 20: 95-101.

8. Raskin R, Meyer D. 2010. Canine and feline cytology: a color atlas and interpretation guide. $2^{\text {nd }}$ ed. St. Louis, USA: Saunders Elsevier. 450 p.

9. Romagnoli $\boldsymbol{F}$. 2006. Infertilidad felina y manejo de un criadero de gatos. En: Wanke M, Gobello C (eds). Reproducción en caninos y felinos domésticos. Buenos Aires: Inter-Médica. p 283-302.

10. Root Kustritz M. 2006. Collection of tissue and culture samples of the canine reproductive tract. Theriogenology 66 : 567-574. doi: $10.1016 / \mathrm{j}$.theriogenology.2006.05.003

11. Sánchez A, Silva M. 2002. Biología de la gestación en la gata doméstica (Felis catus). Arch Med Vet 34: 147-156. doi: 10.4067/S0301-732X2002000200001

12. Sánchez A, Silva M. 2003. Evaluación de respuesta ovárica y calidad de ovocitos en gatas tratadas con hormona folículo estimulante (FSH) utilizando dos esquemas de administración. Arch Med Vet 35: 119-126. doi: 10.4067/S0301732X2003000100014 
13. Schlafer D. 2012. Diseases of the canine uterus. Reprod Dom Anim 47 (Suppl) 6: 318-322. doi: 10.1111/ rda.12064

14. Tsutsui T, Higuchi C, Soeta M, Oba H, Mizutani T, Hori T. 2009. Plasma $\mathrm{LH}$, ovulation and conception rates in cats mated once or three times on different days of oestrus. Reprod Dom Anim 44 (Suppl 2): 76-78. doi: 10.1111/ j.1439-0531.2009.01451.x

15. Tsutsui T, Stabenfeldt G. 1993. Biology of ovarian cycles, pregnancy and pseudopregnancy in the domestic cat. J Reprod Fert Suppl 47: 29-35.

16. Verstegen J. 1998. Phisiology and endocrinology of reproduction in female cats. In: Manual of small animal reproduction and neonatology. UK: British Small Animal Veterinary Association. p 11-16.
17. Walter J, Neuberg K, Failing K, Wehrend A. 2012. Cytological diagnosis of endometritis in the mare: investigations of sampling techniques and relation to bacteriological results. Anim Reprod Sci 132: 178-186. doi: 10.1016/ j.anireprosci.2012.05.012

18. Watts J, Wright P, Lee C. 1998. Endometrial cytology of the normal bitch throughout the reproductive cycle. J Small Anim Pract 39: 2-9. doi: 10.1111/ j.1748-5827.1998.tb03661.x

19. Zambelli D, Prati F. 2006. Ultrasonography for pregnancy diagnosis and evaluation in queens. Theriogenology 66 : 135-144. doi: 10.1016/j.theriogenology.2006.04.004

20. Zar J. 1999. Biostatistical analysis. $4^{\text {th }}$ ed. New Jersey. Prentice Hall. 929 p. 